\title{
Los nuevos mártires de la medicina en el Perú
}

\author{
Paolo A. Wong 1 \\ 1 Médico. Sección Cientifica de Epidemiología, Instituto de Medicina Tropical, Universidad Nacional Mayor de San Marcos. \\ Ex Presidente de la Sociedad Cientifica de San Fernando.
}

\section{Señor Editor,}

El pasado viernes nueve de enero, a las tres de la madrugada, en la ciudad de Piura falleció el médico James Tello Vivanco de veintinueve años de edad, víctima de un lamentable accidente de tránsito. La impactante noticia llegó inmediatamente a sus familiares y causó gran consternación entre todos sus amigos de la Universidad Nacional Mayor de San Marcos de Lima de donde James había egresado meses antes.

El joven galeno -que se encontraba realizando su Servicio Rural Urbano Marginal en Salud (SERUMS) en el caserío de Jicate, en Huancabamba, conocida provincia de la sierra piurana- había logrado establecer un cálido clima de confianza y esperanza en la población, pues, como pocos lugares en las profundidades del Perú, contaban ya con un profesional de la medicina para curarlos con su ciencia o, cuanto menos, consolarlos con su cariño.

A las seis de la tarde, la víspera de su muerte, el doctor Tello recibió una emergencia; esta vez se trataba de una paciente gestante, que tras un rápido abordaje, identificó como de alto riesgo, condición que ponía en aprietos una vez más a su puesto de salud que no contaba con los recursos necesarios para la atención debida ante una posible cesárea o para los cuidados inmediatos del frágil neonato. El médico decidió transferirla a la ciudad de Piura a doscientos treinta kilómetros de distancia.

Tengo que ir con ella -pensó -. En esas seis horas de camino era posible que el parto se desencadene en cualquier momento y entonces la paciente necesitaría atención médica.

Tomó su maletín y subió en la parte trasera del vehículo luego de acomodar a la gestante en la camilla para monitorizarla. En el puesto de salud no quedaba nadie. El doctor y el técnico de enfermería, quien fungiría de chofer, se enrumbaron hacia Piura al caer la tarde del ocho de enero.
La ambulancia, por así llamarle, era una camioneta rural de más de treinta años de antigüedad en cuya tolva se había improvisado una cabina para trasladar a una persona en situación de emergencia y un acompañante que, por lo general, era un familiar, pero en este caso albergaba al doctor James Tello quien iba sentado dando la espalda al ángulo posterior izquierdo del vehículo. Tenía además varios cajones vacíos que alguna vez debieron contener medicamentos e insumos necesarios para una reanimación cardiorrespiratoria o un apoyo ventilatorio manual siquiera. Pero aún así era una de las herramientas más importantes para salvar las vidas de los necesitados huancabambinos desde hacía muchos años.

Faltaban apenas unos kilómetros para llegar a la ciudad de Piura. El reloj marcaba los primeros minutos del nuevo día cuando el chofer fue cegado por dos luces desde lo lejos de la carretera. Comprendió inmediatamente que el coche de enfrente (que después se supo que era un camión de carga que venía en dirección contraria producto de un pestañeo del chofer) iba directamente hacia ellos. El conductor de la ambulancia intentó una maniobra para evitar la colisión y viró abruptamente hacia la derecha evitando el choque frontal; sin embargo, el vehículo pesado logró impactar fuertemente en la parte trasera de la ambulancia, exactamente en el nefasto ángulo posterior izquierdo. Así pasó. Sabemos que James fue trasladado aún con vida al Hospital Cayetano Heredia de Piura pero el severísimo traumatismo craneoencefálico solo les dio a los neurocirujanos la oportunidad de vestirse con la ropa para operar. El doctor Tello dejó de existir bordeando las tres de la mañana del viernes nueve de enero del año dos mil nueve, como dijimos al empezar este escrito.

En casa lo venían extrañando hacía meses, pues por lo lejano de su trabajo, el tercer hijo de la familia Tello Vivanco no pudo pasar las fiestas navideñas ni de año nuevo en su tranquila casa de la urbanización Santa Rosa en el Callao cerca al aeropuerto. Su inmutable serenidad para resolver los problemas cotidianos y, sobre todo, su contagiante sonrisa ante la dificultad eran también echados de menos por parte de sus colegas recién egresados de San Marcos: la promoción "Pedro Ortiz" de la Facultad de Medicina de San Fernando. En esta casa de estudios -y como diría Jack Tello, hermano mayor de James, en el día de su entierro- nuestro amigo "fue verdaderamente feliz", encontró buenos amigos y recibió mucho cariño. Con ellos había planeado ya sus próximas aventuras como cirujano plástico y tenía entre estos a sus futuros pacientes.

Al enterarse de la noticia del fatal accidente, muchos de sus compañeros de promoción viajaron desde los diferentes lugares donde se encontraban realizando la misma labor que James para darle el último adiós. Tras velar su cuerpo en Lima pudieron despedirse de él con homenajes en el Colegio Médico y en su querido San Fernando, lugar al que se dieron cita autoridades como el Ministro de Salud y el Decano de la facultad.

Aquí, a raíz de este caso, todos se enteraban de una triste arista de la realidad del médico peruano que recién egresa: cada año mueren alrededor de cuatro médicos jóvenes que realizan su SERUMS, la mayor parte de estos por accidentes de tránsito u otras actividades vinculadas a su trabajo. Se enteraban que existen muchos casos de colegas que se infectan producto de la exposición a gérmenes (riesgo no exclusivo del SERUMS, más frecuente sobretodo en el residentado o el internado médico) y que tienen que ser atendidos rápidamente. Nos enterábamos todos que, además de esto, un gran número de noveles galenos son violentados en su integridad física y síquica, también en el año del SERUMS. Al escribir sobre ello, recordamos algunos casos similares cuando dirigíamos el Centro de Estudiantes de Medicina; colegas que enfermaron gravemente y que tuvieron que ser socorridos por familiares y amigos, ya que el seguro social, como a todos, nos cubre a partir del tercer mes de empezar a laborar. 
Recuerdo que nos preguntamos al unísono ¿Hasta cuándo? ¿Es acaso normal en otros países que las mentes más jóvenes y algunas de las más privilegiadas de la sociedad -hay quienes lo consideran así- tengan que perderse tan fácilmente?. No existe (o no debiera) lugar en el mundo donde se puede dar alguien ese lujo. Hace solo unos meses murió también otro amigo y destacado ex alumno de la Universidad Federico Villarreal: Joan Pierre Briceño Trujillo, uno de los futuros cirujanos más preclaros que la sociedad hubiera tenido. Él murió junto con su compañera la también médico Cristina Alfaro Llamoca en el año en que realizaban su SERUMS en el departamento de Ayacucho. Y la lista casi llega a la decena en solo un par de años.

Las autoridades responsables seguro que están tomando cartas en el asunto. Sin embargo, un dato frío y concluyente es que la mortal cifra continúa sin cambios.

Claro está que los accidentes de tránsito corresponden a un problema mucho más difícil de solucionar, solo esperamos que la próxima vez que haya la adjudicación de plazas del SERUMS los colegas no tengan que mirarse mejor las caras pues ya estarán informados que, por lo menos, cuatro de ellos no regresarán. ¡No es necesario un 'año de supervivencia' en nuestra tan golpeada sociedad profesional!

El SERUMS es una actividad muy importante para la comunidad y para el médico. Nuestro país, tantos años estancado en el subdesarrollo, no se ha caracterizado por su buena cobertura sanitaria. Indicadores como la mortalidad materna e infantil, la muerte por enfermedades respiratorias, la cobertura de inmunizaciones, los índices de desnutrición o la incidencia de tuberculosis y sus formas evolutivas cada vez más agresivas siempre nos tuvieron en la cola de los países pobres. Pues bien, mucho de ello (no todo) puede explicarse por el crónico y gélido abandono del Estado hacia la salud de su población ejemplificado en la ausencia de establecimientos con profesionales para la atención de ésta (y también en lo mal pagados que se encuentran los pocos que hay). En este contexto, el SERUMS se presenta como una brillante oportunidad para poder cubrir las necesidades de salud de la gente más desfavorecida, para tener madres que den a luz supervisadas por ojos preparados para detectar complicaciones, que sepan derivar cuando sea necesario, que controlen el crecimiento y la inmunización de los futuros presidentes, escritores, agricultores, profesores; que formen y eduquen sobre higiene, prevención, conductas saludables; que administren racionalmente la dación de medicamentos respetando las diferentes tradiciones; que intercedan científicamente por las comunidades ante los abusos medioambientales propios del desenfreno y la ambición; en fin, tantas otras funciones relevantes de un profesional de la salud.

Sin embargo, esta magnífica oportunidad debe concienciarse como temporal y como un plan de contingencia mientras se desarrollan las actividades y se construyen los presupuestos debidos para la atención a la comunidad por personal menos itinerante.

Además, el SERUMS se constituye como la primera prueba profesional para el médico, enfermero, obstetriz, odontólogo, sicólogo, etc; en el inicio de su carrera encomendada a cuidar la salud de la sociedad entera, lo que incluye también el verdadero contacto del recién egresado con la realidad de nuestro país en contraparte a un modelo educativo muchas veces carente de nociones sobre atención primaria.

Esa gran valía del SERUMS, como vemos, viene acompañada lógicamente de un riesgo que, esperemos, cada vez sea menor. El lector debe saber que las plazas para realizar el SERUMS se han triplicado en los últimos años; este aumento de plazas y en una geografía tan agreste como la nuestra puede explicar también el mayor número de accidentes a los que están expuestos.

Asimismo, existen problemas de otra índole (administrativo, académico, salarial, etc.) en el año del SERUMS que no pretendemos referirnos en la presente carta. Por el contrario, esta breve crónica intenta mostrar al lector la abnegada labor que cumple el médico peruano representado por el doctor James Tello Vivanco: lidiar día tras día con la desigualdad y la falta de herramientas en los lugares más pobres del país; cosas tan elementales como un equipo de radio o telefonía, saneamiento para curaciones, medios de transporte adecuados y un sistema de referencia eficiente, farmacias medianamente abastecidas, personal en número mínimo necesario para realizar una atención integral a cada paciente y, sobre todo, condiciones para garantizar que la vida del que va a salvar vidas no sufra algún percance, o peor aún, como en este caso, se pierda definitivamente. Parece complicado, pero la vida de las personas merece el esfuerzo.

Ahora, a pesar de todos los cuidados es evidente que los accidentes pueden darse en cualquier momento. Solo Dios sabe cuándo y cómo y aunque no lo comprendamos hoy Él también sabe el por qué.

Sin proponérnoslo, hemos ejemplificado aquí una prueba más sobre el sublime rol del médico (del profesional de la salud en general) en la comunidad; el mismo que alguna vez fue minimizado por burócratas desligados de nuestra profesión que incluso pretendieron enfrentarnos con nuestros pacientes, con quienes estamos comprometidos desde que decidimos que nos dedicaríamos a esta noble profesión.

Ejemplos como el de los doctores Tello, Briceño, Alfaro y tantos otros robustecen los históricos principios y valores de sacrificio, entrega y dedicación en la medicina peruana.

Hay un agregado al colofón de esta historia. Un hecho que seguramente pasaría desapercibido si el doctor Tello no hubiera muerto. Un hermoso acontecimiento que solo los que tienen la gracia de haber sido seleccionados por la sociedad pueden darse el gusto de ver cotidianamente, pero que en este caso deja de ser uno más: la madre que el doctor James Tello transfirió a Piura afortunadamente no sufrió lesiones por el accidente y dio a luz a un saludable bebé con las atenciones que el ahora fallecido médico había señalado apenas unas horas antes. Un niño. Una nueva vida que simboliza que tener vocación es ser capaz de sacrificios tan altos como éste. Una nueva sonrisa que es la evidencia de la satisfacción póstuma del doctor Tello de ver la misión cumplida, tal vez diciéndonos “' hablamos tío!”. Un nuevo peruano que lleva también como nombre 'James' en homenaje a aquel médico que perdió su vida por salvarle.

\author{
Correspondencia: \\ Paolo Alberto Wong Chero \\ Av. Brigida Silva 239 - Dpto. C-1002 \\ Urb. Maranga, San Miguel \\ Lima 32, Perú \\ Correo-e: pwongc@epiredperu.net
}

